\title{
BMJ Global Health Ethical issues in intervention studies on the prevention and management of diabetes and hypertension in sub- Saharan Africa
}

Elizabeth Shayo, ${ }^{1}$ Marie Claire Van Hout (D) ${ }^{2}$ Josephine Birungi, ${ }^{3}$ Anupam Garrib, Sokoine Kivuyo, ${ }^{1}$ Sayoki Mfinanga, ${ }^{1}$ Moffat J Nyrienda, ${ }^{3,5}$ Ivan Namakoola, ${ }^{3}$ Joseph Okebe, ${ }^{6}$ Kaushik Ramaiya, ${ }^{7}$ Max Oscar Bachmann (1) , ${ }^{8}$ Walter Cullen, ${ }^{9}$ Jeffrey V Lazarus (D) , ${ }^{10,11}$ Geoff Gill, ${ }^{12}$ Tinevimbo Shiri, ${ }^{6}$ Dominic Bukenya, ${ }^{3}$ Hazel Snell, ${ }^{6}$ Mastula Nanfuka, ${ }^{13}$ Luis E Cuevas (D) , ${ }^{4}$ Meshack Shimwela, ${ }^{14}$ Gerald Mutungi, ${ }^{15}$ Joshua Musinguzi, ${ }^{16}$ Janneth Mghamba, ${ }^{17}$ Kenneth Mugisha, ${ }^{13}$ Shabbar Jaffar (D) , ${ }^{6}$ Peter G Smith, ${ }^{18}$ Nelson Kaulukusi Sewankambo ${ }^{19}$

To cite: Shayo E, Van Hout MC, Birungi J, et al. Ethical issues in intervention studies on the prevention and management of diabetes and hypertension in sub-Saharan Africa. BMJ Global Health 2020;5:e002193. doi:10.1136/ bmjgh-2019-002193

Handling editor Seye Abimbola

$\mathrm{ES}, \mathrm{MCVH}$ and JB contributed equally.,

SJ, PGS and NKS contributed equally.

Received 29 November 2019 Revised 2 June 2020 Accepted 5 June 2020

Check for updates

(c) Author(s) (or their employer(s)) 2020. Re-use permitted under CC BY-NC. No commercial re-use. See rights and permissions. Published by BMJ.

For numbered affiliations see end of article.

Correspondence to Dr Shabbar Jaffar; shabbar.jaffar@|stmed.ac.uk

\section{INTRODUCTION}

The incidence of diabetes and hypertension has risen sharply in sub-Saharan Africa alongside a continuing high burden of HIV infection. ${ }^{1}$ In many settings, the prevalence figures among adults are $4 \%-5 \%$ for diabetes, above $25 \%$ for hypertension and 5\%-20\% for HIV infection. $^{2-4}$ All these conditions require lifelong treatment, and they have increased substantially the demand for chronic care services in Africa, where health systems have, until recently, focused on tackling acute infectious diseases. ${ }^{5}$

There is considerable inequity in service provision for chronic diseases. HIV services, including antiretroviral therapy, are available widely for free and are organised typically in stand-alone clinics. Over $65 \%$ of people estimated to be living with HIV infection are in regular care. ${ }^{6}$ In contrast, this figure is only about $5 \%-20 \%$ for people living with diabetes or hypertension. ${ }^{37} \mathrm{~A}$ major challenge is that medicines for diabetes and hypertension are generally not provided free of charge and have to be purchased by patients. Even in those countries that do provide free medicines for hypertension and diabetes, shortages are common and patients then have to purchase the medicines from private suppliers.

Our research collaboration is evaluating a biomedical diabetes preventive intervention in people living with HIV infection in a placebocontrolled randomised trial and, separately, evaluating integrated healthcare provision compared with standard care for people living

\section{Summary box}

Conducting intervention studies in Africa, where medicines supply for chronic conditions is inequitable and patchy, raises major ethical issues.

- Here we discuss what should the ethical approach be for a research programme in terms of provision of a steady and sustainable supply of medicines for patients with diabetes and hypertension.

with HIV, diabetes or hypertension in a clusterrandomised controlled trial. ${ }^{8}$ There are no data on the effectiveness of these approaches from Africa. Therefore, these trials have clinical and health economic endpoints and the research is underpinned by an implementation research approach, which, for example, requires strong engagement with health policy makers.$^{9-12}$

We discuss the implications of a limited supply of medicines and potential solutions to track the equity of medicine supply. In particular, we consider what should the ethical approach be for a research programme in terms of provision of a steady and sustainable supply of medicines for patients with diabetes and hypertension when alternative affordable and accessible supplies are unavailable?

\section{POSSIBLE SOLUTIONS AND LESSONS FROM OTHER CONTEXTS}

Should the research be conducted in realworld conditions where medicines supply for hypertension and diabetes is patchy?

If we conduct the research within the context of real-world conditions, then, under the 
integrated care model that we are testing, patients with different conditions would sit together in the same clinic and have consultations with the same healthcare providers. It will be morally challenging for clinical staff and researchers to turn away one group of patients because of a lack of medicines while for others, with HIV infection, treatment is available freely. In the past, in the vertical stand-alone models of care, the ethical dilemma was less stark because HIV and diabetes/hypertension clinics operated at different locations, sometimes on different days and involved different clinicians.

As well as the issue of inequity, observing people living with diabetes and hypertension unable to access medicines, which are both low-cost and effective, could break the ethical principle of beneficence, which states that researchers should have the welfare of the participants as a goal. $^{12}$

Also, if the research is conducted to real-world conditions, it may be of limited relevance by the time it is completed. This is because the provision of medicines for chronic disease management in Africa is likely to increase in the next few years with the increased pressure that is now on donors and governments to support these treatment programmes. If drug shortages decrease, then the findings of our research programme, which would be available in a few years' time, would be of very limited relevance when they are published.

Thus, in our view, there are both moral and scientific reasons for ensuring patients entering such intervention studies have access to uninterrupted supplies of medicines for the duration of the research.

\section{Should the research programme purchase the medicines for participants to enable the research to run smoothly?}

If the study identifies a model of care that is costeffective, it could give impetus to government health services to strengthen their medicine supply chains. On the contrary, by carrying the cost that should be met by governments and donors, it could potentially reduce the pressure on health authorities to find solutions, weaken the advocacy for patients' rights and inhibit the public from demanding their rights to access treatments. Advocacy for the right to access antiretroviral therapy was crucial in HIV control in Africa ${ }^{13}$ and will likely play a major role in enhancing access to medicines for diabetes and hypertension.

If the research programme provides the medicines for study participants, it would not be sustainable beyond the duration of the research programme and would mean that patients who access treatment services today may have to stop taking their medicines when the study finishes. While the study is running, provision of free drugs would be a strong incentive for participants to join the study. Patients will have the right to decline and to receive the care they would otherwise have received, but if this means a less reliable supply of medicines (than in the research programme), then patients are very likely to join the research. The issue is whether or not this is undue coercion.

In our view, the ideal situation here is that access to medicines is strengthened for all, ideally by Ministries of Health. For this to happen, researchers must work in partnership with policy makers and disease control managers, that is, policy makers and disease control managers must have ownership of the research. Researchers should be prepared to purchase medicines for short-term use to cover any gaps that might occur. Where Ministries of Health cannot achieve a reliable supply, even with the support of research programmes, then research in those settings may not be feasible.

\section{Is there an obligation to provide medicines to non-trial participants?}

Another ethical dilemma arises because the research programme will include only a fraction of all the patients with the target conditions attending the clinics and patients not in the research studies will not have access to any enhanced treatment. Although the costs of treatment for diabetes and hypertension are relatively low, it is most unlikely that a research programme could bear the costs of treating large numbers of non-study participants and a requirement to do so would make the research nonviable.

Not providing medicines to non-study participants will cause inequity between patients in the trial and those who are not. It could compromise outcomes if participants share their medicines to spread the benefits, for example, with relatives with chronic conditions not in the study. It may also endanger community support for the study if this sends the message that we do not care about family members.

There is no precedence with provision of drugs to large numbers of non-study participants. When combination antiretroviral therapy for HIV was introduced in high-income countries, it was not available in public health clinics in Africa because of its high cost. Research in Africa at that time will have faced similar dilemmas but wide-scale provision only occurred more recently. At that time, there were also some calls that the standards in clinical trials around treatment and access to medicines should be the same in Africa as in high-income countries. ${ }^{14}$ However, the standardisation would have inhibited HIV research in Africa and was opposed by global health researchers. ${ }^{15}$ This enabled the research to be conducted quickly and at relatively low cost, and research on the prevention and management of diabetes and hypertension may need similar considerations. Thus, although not ideal, priority of medicines for research subjects will be essential in some settings where the supply of medicines cannot be strengthened for all.

\section{Should the health facilities be encouraged to procure a greater supply of medicines to facilitate the research?}

In some circumstances, health facilities might be able to procure a greater supply of medicines to facilitate the 
research. In countries such as Tanzania and Uganda, under district fiscal decentralised systems, health facilities have flexibility in how they spend their resources.

However, if the supply of medicines for diabetes and hypertension was augmented in this way, this could be at the expense of service provision for other conditions, raising further ethical concerns. Moreover, there are clear ethical issues if health facilities procure medicines to support a research programme without ensuring that this supply will be maintained after the study.

The ideal solution here is that health facilities are supported to strengthen all medicines supply, not just for diabetes and hypertension.

\section{CONCLUSION}

Research to inform strategies for the prevention and management of diabetes and hypertension is vital in Africa. However, such research raises complex ethical issues relating to the limited supply of medicines and a pragmatic approach specific to the African context is needed.

It is clear that the research would likely produce meaningless results if the supply of medicines was erratic, but equally, the research programme cannot just purchase the necessary drugs for its trial participants. A solution to this conundrum has to be through discussion and working in partnership with the key stakeholders: the policy makers, disease control managers, healthcare providers, patient groups and community representatives. Indeed, a fundamental ethical requirement is meaningful engagement with the key stakeholders. ${ }^{1011}$

Similar issues arose in the early years of research on HIV treatment in Africa when antiretroviral therapy was prohibitively expensive and not available widely. The research that was conducted in these situations precipitated later pressure on the international community to ensure that life-saving medicines were made freely available to people living with HIV. HIV care and prevention would not have reached its current level without overcoming the initial obstacles to research on treatment. There is a pressing need to take on board the lessons from the progress made with HIV control to develop and expand research on diabetes and hypertension control.

We have used our studies on three specific diseases-HIV infection, diabetes and hypertension-to highlight the ethical dilemmas, but the ethical challenges are likely to be common to other diseases.

\footnotetext{
Author affiliations

${ }^{1}$ National Institutes for Medical Research, Dar es Salaam, United Republic of Tanzania

${ }^{2}$ Faculty of Education, Health \& Community, Liverpool John Moores University, Liverpool, UK

${ }^{3}$ MRC/UVRI \& LSHTM Uganda Research Unit, Entebbe, Uganda

${ }^{4}$ Department of Clinical Sciences, Liverpool School of Tropical Medicine, Liverpool, United Kingdom

${ }^{5}$ Faculty of Epidemiology and Public Health, London School of Hygiene and Tropical Medicine, London, UK
}

${ }^{6}$ Department of International Public Health, Liverpool School of Tropical Medicine, Liverpool, UK

${ }^{7}$ Shree Hindu Mandal Hospital, Dar es Salaam, Tanzania

${ }^{8}$ Norwich Medical School, Faculty of Medicine and Health Sciences, University of East Anglia, Norwich, UK

${ }^{9}$ School of Medicine, University College Dublin, Dublin, Ireland

${ }^{10} \mathrm{Hospital}$ Clinic, University of Barcelona, Instituto de Salud Global de Barcelona, Barcelona, Spain

${ }^{11} \mathrm{CHIP}$, Rigshospitalet, Kobenhavn, Denmark

${ }^{12}$ Emeritus Professor of International Medicine, Liverpool School of Tropical Medicine, Liverpool, United Kingdom

${ }^{13}$ The AIDS Support Organisation, Kampala, Uganda

${ }^{14}$ Temeke Hospital, Dar es Salaam, Tanzania

${ }^{15}$ Non-communicable Disease Control Programme, Ministry of Health, Kampala, Uganda

${ }^{16}$ AIDS Control Programme, Ministry of Health, Kampala, Uganda

${ }^{17}$ Department of Preventive Services, Ministry of Health and Social Welfare, Dar es Salaam, Tanzania

${ }^{18}$ MRC Tropical Epidemiology Group, Faculty of Epidemiology and Population Health, London School of Hygiene and Tropical Medicine, London, UK

${ }^{19}$ College of Health Sciences, Makerere University, Kampala, Uganda

Twitter Jeffrey V Lazarus @JVLazarus

Contributors ES, AG, JB and SJ wrote the first draft. MCVH made substantial contributions following the review by the journal. All the authors contributed to many iterations.

Funding This research was funded by the National Institute for Health Research (NIHR) (project reference 16/137/87) using UK aid from the UK Government to support global health research. The views expressed in this publication are those of the author(s) and not necessarily those of the NIHR or the UK Department of Health and Social Care. The project has received funding from the European Union's Horizon 2020 research and innovation programme under grant agreement No 825698.

Disclaimer The views expressed in this publication are those of the author(s) and not necessarily those of the NIHR or the UK Department of Health and Social Care or the European Union.

Competing interests None declared.

Patient consent for publication Not required.

Provenance and peer review Not commissioned; externally peer reviewed.

Data availability statement № additional data are available.

Open access This is an open access article distributed in accordance with the Creative Commons Attribution Non Commercial (CC BY-NC 4.0) license, which permits others to distribute, remix, adapt, build upon this work non-commercially, and license their derivative works on different terms, provided the original work is properly cited, appropriate credit is given, any changes made indicated, and the use is non-commercial. See: http://creativecommons.org/licenses/by-nc/4.0/.

\section{ORCID iDs}

Marie Claire Van Hout http://orcid.org/0000-0002-0018-4060

Max Oscar Bachmann http://orcid.org/0000-0003-1770-3506

Jeffrey V Lazarus http://orcid.org/0000-0001-9618-2299

Luis E Cuevas http://orcid.org/0000-0002-6581-0587

Shabbar Jaffar http://orcid.org/0000-0002-9615-1588

\section{REFERENCES}

1 GBD 2016 Causes of Death Collaborators. Global, regional, and national age-sex specific mortality for 264 causes of death, 19802016: a systematic analysis for the global burden of disease study 2016. Lancet 2017:390:1151-210.

2 UNAIDS. Global HIV and AIDS statistics. 2019 Factsheet. Available: https://www.unaids.org/en/resources/fact-sheet [Accessed 10 Mar 2020].

3 Atun R, Davies JI, Gale EAM, et al. Diabetes in sub-Saharan Africa: from clinical care to health policy. Lancet Diabetes Endocrinol 2017:5:622-67.

4 World Health Organisation. Global health Observatory data: raised blood pressure. Available: https://www.who.int/gho/ncd/risk factors/ blood_pressure_prevalence_text/en/ [Accessed 10 Mar 2020]. 
5 Kruk ME, Nigenda G, Knaul FM. Redesigning primary care to tackle the global epidemic of noncommunicable disease. Am J Public Health 2015;105:431-7.

6 World Health Organisation. Global health Observatory data. antiretroviral therapy coverage among all age groups. Available: https://www.who.int/gho/hiv/epidemic_response/ART/en/ [Accessed 10 Mar 2019].

7 Addo J, Smeeth L, Leon DA. Hypertension in sub-Saharan Africa: a systematic review. Hypertension 2007;50:1012-8.

8 Garrib A, Birungi J, Lesikari S, et al. Integrated care for human immunodeficiency virus, diabetes and hypertension in Africa. Trans $R$ Soc Trop Med Hyg 2018.

9 Gopichandran V, Luyckx VA, Biller-Andorno N, et al. Developing the ethics of implementation research in health. Implement Sci 2016;11:161.
10 Peters $\mathrm{DH}$, Adam T, Alonge O, et al. Implementation research: what it is and how to do it. BMJ 2013;347:f6753.

11 Theobald S, Brandes N, Gyapong M, et al. Implementation research: new imperatives and opportunities in global health. Lancet 2018;392:2214-28.

12 World Health Organisation. Ethical considerations for health policy and systems research. Geneva: World Health Organization, 2019.

13 Smith JH, Whiteside A. The history of AIDS exceptionalism. J Int AIDS Soc 2010;13:47.

14 Angell M. The ethics of clinical research in the third World. $N$ Engl J Med 1997;337:847-9.

15 Aaby P, Babiker A, Darbyshire J, et al. Ethics of HIV trials. Lancet 1997;350:1546. 